\title{
Inmigraciones europeas en Latinoamérica: inmigrantes polacos en la región de Curitiba/PR (Brasil) ${ }^{1}$
}

\author{
Imigrações europeias na América Latina: imigrantes poloneses na região \\ de Curitiba/PR (Brasil)
}
European immigration in Latin America: polish immigrants in Curitiba/PR (Brazil) area

\author{
Me. Marcos Roberto Pisarski Junior
}

\begin{abstract}
Resumen
Esta investigación tiene como objetivo presentar y discutir la inmigración polaca desde finales del siglo XIX y principios del XX hasta el contexto latinoamericano de Brasil, especialmente centrado en la región de la ciudad de Curitiba/PR. A través de una densa revisión bibliográfica, esta investigación presenta datos históricos y sociales que presentan las razones, etapas e impactos de la inmigración de este grupo étnico a Brasil. En un segundo paso, hay una presentación de hechos que demuestran la importancia de esta inmigración en la región, que se discuten y exponen más adelante como conclusión de la investigación.
\end{abstract}

Palabras claves: América Latina; Cultura; Curitiba/PR; Inmigración; Polacos.

\section{Resumo}

Esta pesquisa tem como objetivo apresentar e debater a imigração polonesa do final do século XIX e início de século XX para o contexto latinoamericano do Brasil, especialmente focado na região da cidade de Curitiba/PR. Por meio de uma densa revisão bibliográfica, esta pesquisa apresenta dados históricos e sociais que apresentam os motivos, etapas e impactos da imigração desta etnia para o Brasil. Em um segundo momento é realizado uma exposição de fatos que demonstram a importãncia desta imigração na região, que são debatidos e expostos posteriormente como conclusão da pesquisa.

Palavras-Chave: América Latina; Cultura; Curitiba/PR; Imigração; Poloneses.

\begin{abstract}
This research aims to present and discuss Polish immigration from the late 19th and early 20th centuries to the Latin American context of Brazil, especially focused on the region of the city of Curitiba/PR. Through a dense bibliographic review, this research presents historical and social data that present the reasons, stages and impacts of immigration of this ethnic group to Brazil. In a second step, there is a presentation of facts that demonstrate the importance of this immigration in the region, which are discussed and exposed later as a conclusion of the research.
\end{abstract}

Keywords: Culture; Curitiba/PR; Immigration; Latin America; Poles.

\section{Introducción}

\footnotetext{
${ }^{1}$ Mestre em Turismo - UFPR; Professor na Universidade Estadual de Goiás - UEG / Pesquisador-Associado no Centro Latino-Americano de Estudos em Cultura - CLAEC; Caldas Novas, Goiás, Brasil; marcos.pisarski@gmail.com
} 
La historia de la humanidad está formada por varios aspectos de la transformación social que a menudo incluyen la consecuencia de que los pueblos o las etnias abandonen su región de origen, con mayor frecuencia de forma forzada, y se trasladen a otras regiones distantes y en otros contextos.

A lo largo de los siglos, el continente europeo ha sufrido varias e intensas transformaciones, tanto en materia de arreglos políticos como geográficos, lo que lo convierte en un escenario dinámico que ha llevado a que una gran parte de su población se vea obligada a emigrar a otras regiones.

Dentro de estas dinámicas migratorias, se encontró la peculiaridad del grupo étnico polaco, en su mayoría perteneciente al Reino de Polonia, pero que después de la caída del reino, la dominación y el reparto de su territorio entre las 3 potencias emergentes de la época: el Imperio ruso, el Imperio austrohúngaro y Reino de Prusia: fue oprimido y humillado, lo que provocó que una gran parte de su población migrara a otras regiones del mundo.

En ese momento, los principales países fuera del continente europeo que recibieron a estos inmigrantes polacos fueron Estados Unidos, Brasil, Argentina, Australia y Canadá, lo que cambió el contexto étnico y cultural de su grupo y dónde se establecieron.

En Brasil, la inmigración comenzó en la segunda mitad del siglo XIX, y se realizó en un principio con el apoyo del Estado brasileño, sin embargo, con el tiempo, estos aspectos han cambiado. Por lo tanto, una gran parte de los inmigrantes polacos en Brasil tuvo muchas dificultades para establecerse en el país.

Una de las regiones de Brasil que más recibió este flujo migratorio de polacos fue la región de la ciudad de Curitiba/PR, al este del estado de Paraná, en el sur de Brasil, y que con los años se ha convertido en el segundo centro migratorio más grande para los polacos. el mundo, solo superado por la ciudad de Chicago / IL en los Estados Unidos.

Por lo tanto, este trabajo busca presentar y discutir aspectos de la inmigración polaca a la ciudad de Curitiba/PR, demostrando la influencia de este grupo étnico en la región y el legado de la cultura polaca y de sus inmigrantes en el contexto social y político de la ciudad.

Para la realización de este artículo, fue realizada una pesquisa exploratoria basada en estudios bibliográficos de artículos, disertaciones, tesis y libros que exponen y debaten el proceso de migración de los polacos a la región de la ciudad de Curitiba/PR. (GIL, 2002) 
Al final de esta pesquisa, se exponen algunos apuntamientos que ratifican la hipótesis inicial de este trabajo, acerca de la influencia de la etnia polaca en el contexto social y cultural de la ciudad de Curitiba/PR y región metropolitana, y transmite las conclusiones de la discusión que fue trabajada al largo del artículo.

La historia de América Latina está formada por un contexto global que incluye a los pueblos nativos, la colonización bárbara europea de la era de los descubrimientos, la esclavitud en el continente, la (re) independencia latinoamericana y los nuevos procesos de inmigración que han ocurrido y continúan ocurriendo en el continente.

Comprender el pasado es comprender lo que sucederá, y en el contexto latinoamericano esto no es diferente.

\section{La inmigración polaca en la región de Curitiba/PR}

El proceso migratorio europeo en Brasil comenzó en el siglo XIX, y en la segunda mitad de ese siglo se solidificó, principalmente debido al hecho de que el Estado brasileño está haciendo campaña en el extranjero para atraer inmigrantes europeos a regiones con menor densidad de población.

Este proceso fue una consecuencia de la situación y las condiciones enfrentadas en la vida cotidiana europea que estaban experimentando varias transformaciones en su estructura, como lo señaló Adamoski (2013), cuestiones como la división desigual de la tierra en el período post feudal, donde pocos acumulaban grandes porciones de tierra productiva y la gran mayoría tuvo que someterse a condiciones de trabajo terribles para mantener la supervivencia de su familia o migrar a los centros urbanos industrializados recién formados debido a la reciente revolución industrial, el crecimiento demográfico entre otros aspectos socioeconómicos, favoreció la aparición de olas de inmigración europeas para los Continente americano y más específicamente a Brasil.

En el caso de la inmigración polaca a Brasil, este fenómeno ocurrió en 1869, con la llegada de un grupo de familias polacas. Este grupo se estableció en la costa norte del estado de Santa Catarina, según lo declarado por Reis y Silveira (2008):

Os primeiros representantes do grupo étnico polonês chegaram ao Brasil em 1869. Um grupo de 16 famílias, com aproximadamente 80 pessoas, provenientes da localidade de Siolkowice, região de Opole, província da Silésia, então sob ocupação prussiana, fixou-se numa área de terras da Colônia Príncipe Dom Pedro, próxima à Colônia Itajaí, atual município de Brusque-SC. (REIS; SILVEIRA, 2008 p. 02) 
A su vez, el tema de la inmigración polaca a Brasil tenía otros elementos que eran más relevantes para el evento de las olas de inmigración, en el que se destacaba la situación política y nacional polaca. Como lo cita Doustdar (1990):

Em fins do século XVIII, a Polônia desapareceu como nação livre e independente, transformando-se num pedaço de chão da periferia oriental dos grandes centros de decisão localizados no ocidente da Europa. Frente a uma Europa que emergia da Revolução Industrial, a Polônia sofria ainda os efeitos das forças medievais, principalmente de uma população camponesa feudalizada. Associado a isso, havia o domínio da ação conjunta de três potências ocupantes: a Áustria, a Prússia e a Rússia. (DOUSTDAR, 1990, p. 76)

Debido a estos problemas, la población polaca comenzó su proceso de inmigración sin pertenecer a su país de origen, que había dejado de existir como un estado independiente, sino como una nación polaca, según lo declarado por Iarochinski (2000):

Quando a imigração polaca começou no Brasil, não existia o Estado Polaco, somente a nação. A Polônia, após ter sido um dos maiores países europeus nos séculos XVI e XVII, foi invadida no século dezoito pelos seus três vizinhos, Rússia, Áustria e Prússia. (IAROCHINSKI, 2000, p.64)

La Figura 1 representa la región anteriormente entendida como el Estado de Polonia y que fue compartida desde el final del siglo XVII hasta el final del siglo XIX por Rusia (tonos verdes), Prusia - Actual Alemania - (tonos azules) y el extinto Imperio Austrohúngaro (amarillo y naranja). 


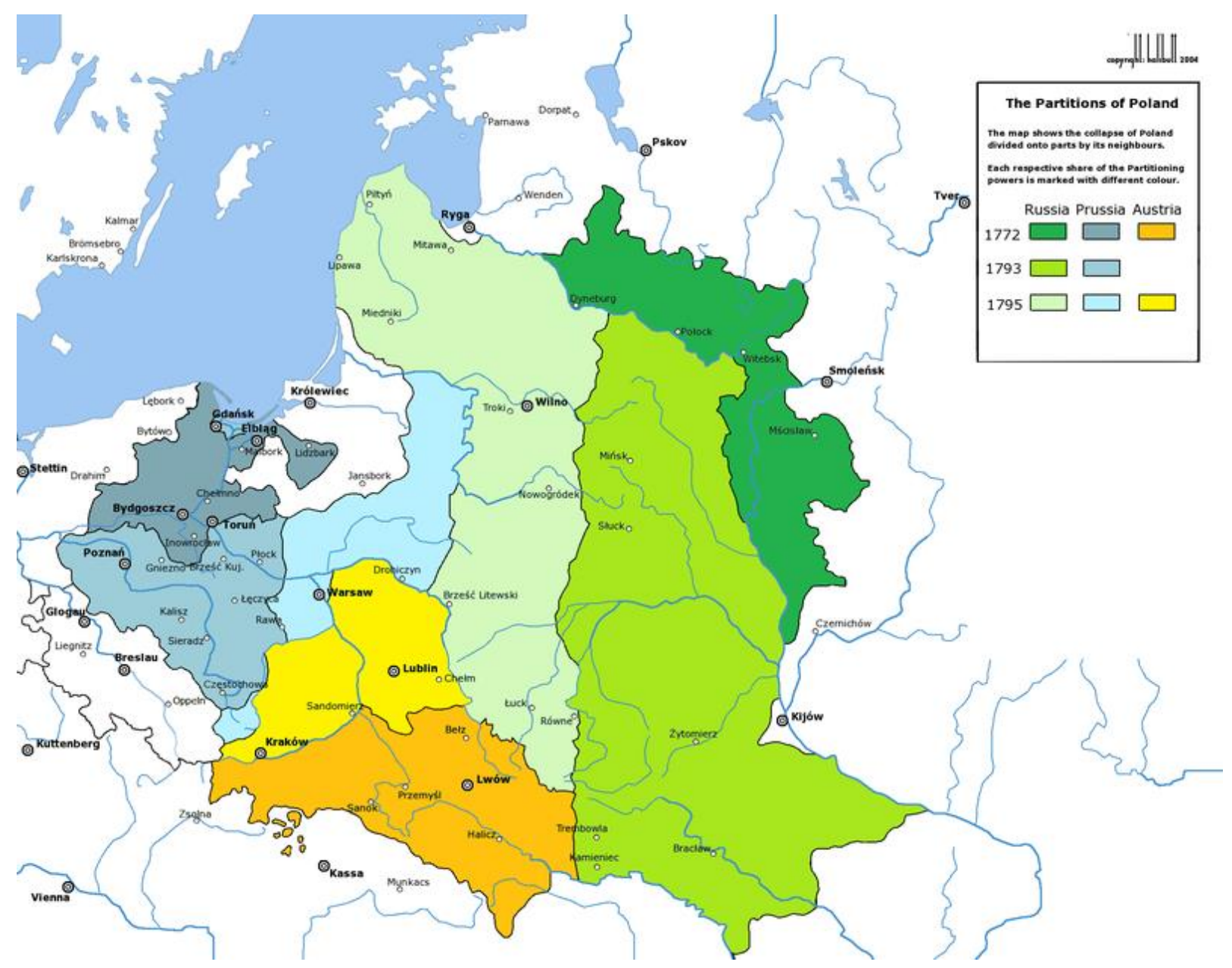

Figura 1 - Mapa de la partición de Polonia

Fuente: Wikipedia.org

Mientras estos procesos sociales se llevaban a cabo en el viejo continente, en Brasil, y en parte de Sudamérica, hubo una serie de fenómenos sociopolíticos que contribuyeron a hacer del país, y la región, uno de los principales destinos para las etnias europeas inmigrantes, como polacos, ucranianos, rusos y otros.

Con el proceso de abolición de la esclavitud en Sudamérica (1850-1888), el trabajo esclavo de africanos negros tuvo que dejar de ser explotado y con eso surgió una necesidad para los países y principalmente para el Estado brasileño: el de tener mano de obra calificada para la producción agrícola nacional. Como lo cita Santos (2008):

O tráfico negreiro, enfim, chegaria ao fim. A reposição de mão-de-obra escrava vinda da África deixaria de existir, e juntamente com ele um dos grandes fatores de acumulação lusa no Brasil-Colônia e posteriormente Império. Porém, o tráfico em si não cessa plenamente no Brasil. A rápida expansão da economia cafeeira gera uma crescente demanda por mão-de-obra. (SANTOS, 2008, p. 11) 
Por esta razón, el gobierno brasileño invirtió en publicidad e hizo factibles las políticas de incentivos para atraer inmigrantes europeos al territorio nacional. Como cita Bueno (1996, p.14-15) "Em busca de mão de obra para as lavouras, as autoridades brasileiras promoveram na Europa uma intensa propaganda sobre a fertilidade das terras brasileiras", complementando que:

\begin{abstract}
Com o intuito de promover a vinda de europeus para o trabalho agrícola nas terras brasileiras, as companhias de imigração divulgavam as vantagens oferecidas pelo sistema de imigração brasileiro. As companhias instaladas em diferentes países ofereciam passagens gratuitas aos emigrantes que quisessem tentar a sorte em outros lugares. A pretensão de organizar o caos reinante nas cidades europeias, decorrente do crescimento populacional, facilitava e impelia a saída dos desempregados, o excedente da população rural, os desclassificados que vagavam nas ruas dos centros urbanos, os velhos e as famílias numerosas. (BUENO, 1996, p. 15)
\end{abstract}

Aliado a esto, uno de los mayores intereses de los inmigrantes polacos y de otros europeos era conquistar su derecho a la propiedad, el trabajo decente, la libertad y estar lejos de las guerras y los dominios que devastaron sus medios de vida, como dice Gritti (2004, p.33): "Não é difícil imaginarmos quanto era atrativo o Brasil para os camponeses de então, principalmente se considerarmos a pobreza que sofriam antes da emigração"

A partir de estas políticas de incentivos para la movilización de inmigrantes europeos a Brasil y el gran interés que se generó en tierras europeas, se produjeron olas de inmigración que transformaron el escenario sociocultural nacional, y especialmente en la región sur del país.

La política de inmigración promovida por el gobierno brasileño, desde el principio, causó preocupación a los gobernadores de la provincia de Paraná. Sus intenciones eran colonizar las vastas áreas geográficas deshabitadas del estado y cultivar el suelo para proporcionar productos esenciales.

Para esto, el gobierno de la provincia de Paraná ofreció instalaciones para estos inmigrantes, desde su llegada a los puertos brasileños hasta su asentamiento en las colonias de inmigrantes ya fundadas en Paraná, según lo declarado por Bueno (1996):

O objetivo era povoar os imensos territórios, levar vida aos sertões desabitados, estabelecer colônias agrícolas para a produção de gêneros de primeira necessidade. Para que os imigrantes fossem atraídos a um país ainda escravocrata, os administradores empenhavam-se em oferecer-lhes agasalhos, alimentos e atendimento desde o desembarque nos portos até a sua instalação nas colônias. (BUENO, 1996, p. 12) 
Sin embargo, como el flujo de inmigración en Paraná, y aún más cerca de los centros urbanos ya establecidos, fue intenso, comenzaron a ocurrir problemas en los asentamientos de las colonias para estos inmigrantes, especialmente polacos y ucranianos, como afirma Kravczyk (2013):

O governo brasileiro não conseguiu acomodar os imigrantes poloneses em terras férteis, propensas para a agricultura como havia prometido. Esses imigrantes quando chegavam aos locais designados pelo governo brasileiro nos estados do Sul, geralmente encontravam um habitat impróprio para fixar moradia e desenvolver a agricultura, visto que as colônias alemãs e italianas que estavam em franco desenvolvimento já possuíam os melhores lotes de terra. Como não havia lotes demarcados nem locais para instalar um número tão grande de pessoas, os imigrantes poloneses foram alojados em diversos locais. (KRAVCZYK, 2013, p.12)

De hecho, la cuestión de la asignación de tierras terminó favoreciendo a ciertos grupos étnicos, como alemanes e italianos, que se establecieron cerca de centros urbanos y en tierras fértiles. Sin embargo, este proceso obstaculizó el asentamiento de inmigrantes polacos recién llegados, lo que también señala Polanczyk (2010), cuando dice acerca de los inmigrantes polacos y ucranianos:

Os poloneses e ucranianos não foram instalados, foram "espalhados" onde era possível: Espirito Santo, Mato Grosso, nos cafezais de São Paulo, na cidade de São Paulo, Minas Gerais, Paraná, Santa Catarina e Rio Grande do Sul. Foram colocados em colônias alemãs, italianas, nos piores pedaços de terra, aqueles rejeitados por outros imigrantes. (POLANCZYK, 2010, p. 24)

Junto a este punto, otro aspecto importante que contribuyo para este proceso fue que el las regiones urbanas, o más próximas a estas, habían grandes poblaciones de inmigrantes alemanes, pueblo este que dominaba y oprimía los polacos después de la dominación de su territorio en los siglos XVIII y XIX, no permitiendo el uso de su idioma y culturas. (DOUSTDAR, 1990; PISARSKI JUNIOR, 2019)

Como resultado, los inmigrantes polacos, que en su mayor parte estaban vinculados a la agricultura, tuvieron que alejarse de los centros urbanos y de las tierras fértiles cercanas a estos centros, quedando al margen de las aglomeraciones demográficas. "Neste período, 95\% dos poloneses recém-chegados eram agricultores”. (OLIVEIRA, 2009, p.4)

En este proceso de migración y asentamiento en un local, parte de los inmigrantes polacos se establecieron en el estado de Paraná, siendo los primeros en llegar desde el estado vecino de Santa Catarina, donde se habían establecido previamente, como cita Reis y Silveira (2009): 
No Paraná, estudos apontam o ano de 1871 como marco principal da vinda dos poloneses, ou seja, dois anos depois de se fixarem em Santa Catarina. Nessa data, o grupo já ampliado, chegou a Curitiba, instalando-se no bairro do Pilarzinho[...] Em Curitiba, fundaram várias colônias que hoje são, por exemplo, os bairros de Santa Cândida e Abranches. (REIS; SILVEIRA, 2009, p. 06)

Así como aconteció en Curitiba/PR, grande parte de los inmigrantes polacos que se asentaran en el territorio paranaense solamente logro encontrar tierras fértiles para producción al interior del estado de Paraná, se alojando en el centro-sur del estado, como por ejemplo en la región de Irati/PR. (TELEGINSKI, 2016)

Sin embargo, los siguientes grupos de inmigrantes polacos que llegaran en el estado de Paraná, sobre todo en la región de Curitiba/PR, no pudieron establecerse en grandes centros urbanos, teniendo que permanecer en regiones más distantes, ya que en general "os imigrantes eram acomodados na periferia da cidade" (BUENO, 1996, p. 36.)

Este proceso se dio por todo el estado de Paraná, haciendo que los imigrantes polacos se quedasen cada vez más en el interior del estado y más lejos de los centros urbanos. Para ilustrar esta afirmación, Reis y Silveira (2009) presentan la figura 2, donde se presenta un mapa de la distribución de la inmigración polaca en el estado de Paraná:

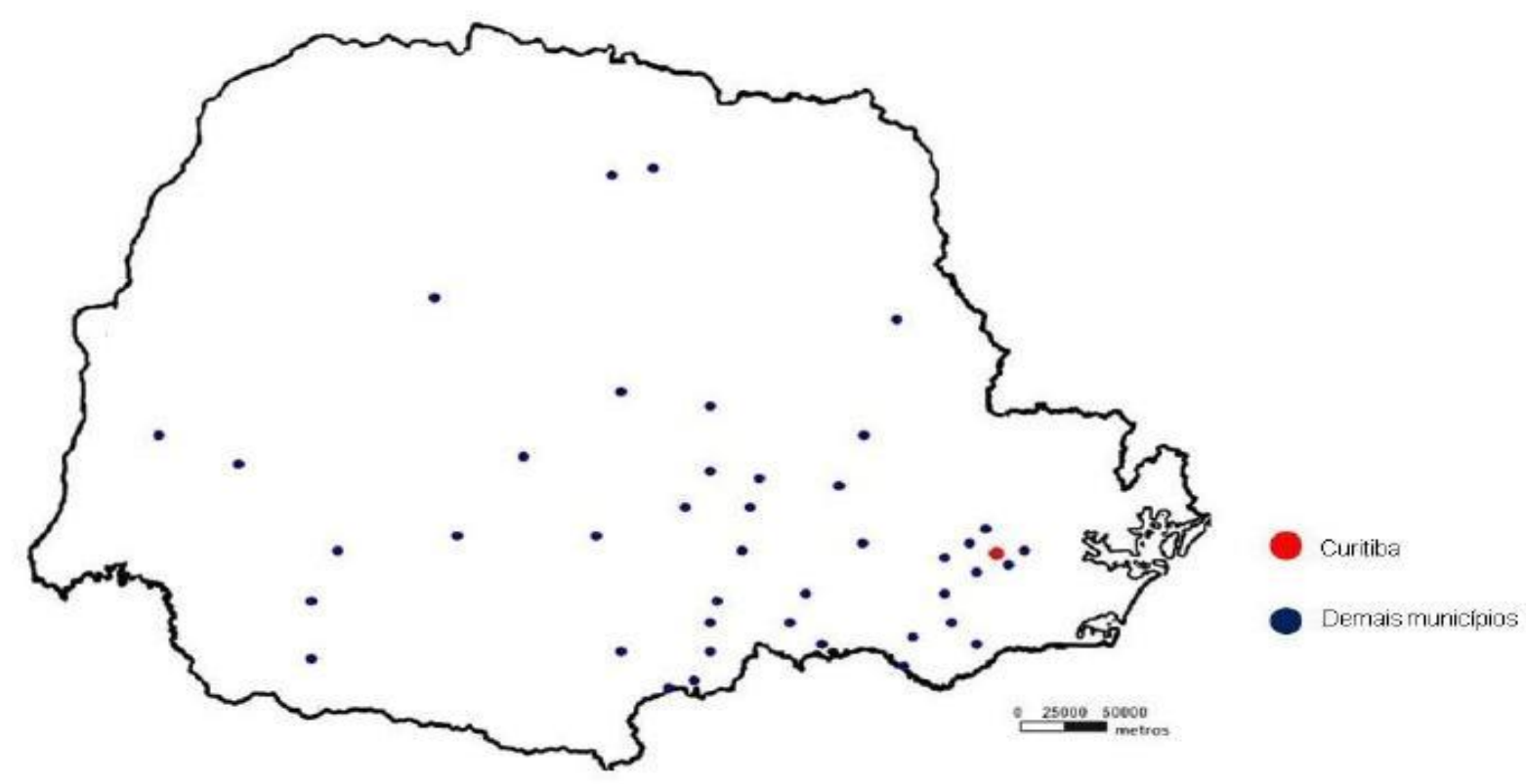

Figura 2 - Distribución de la inmigración polaca en el estado de Paraná

Fuente: Reis y Silveira (2009) 
El mapa que se muestra en la figura 2, colabora con las reflexiones ya presentadas de que la forma de distribución de la inmigración polaca ha sido marginada. Por lo tanto, es posible observar la inmigración polaca en cinco municipios alrededor de la ciudad de Curitiba/PR.

Un reflejo de la densa inmigración polaca en la región de Curitiba/PR es que en solo cinco años desde la llegada de los primeros migrantes, la población de inmigrantes casi llegaba a el número de cuatro mil personas, como afirman Reis y Silveira (2008, p. 8) y que "1876, as colônias polonesas no entorno de Curitiba/PR contavam com 3850 pessoas".

De esta manera, la distribución demográfica de los inmigrantes polacos se produjo en la gran mayoría en los márgenes de la región de Curitiba/PR, donde "os colonos de Tomás Coelho penetraram também nas terras do município de Campo Largo e atingiram também as terras de Palmeira" (DOUSTDAR, 1990, p. 3).

Regiones ocupantes que hasta entonces estaban deshabitadas y eliminadas y que hoy forman parte de varios municipios de la región metropolitana de Curitiba/PR, como Araucária, Campo Largo, Contenda, Piraquara, Pinhais y São José dos Pinhais. (DOUSTDAR, 1990)

\section{Los impactos de la inmigración polaca}

La inmigración polaca en la región de Curitiba/PR y en todo el estado del Paraná se demostró esencial para la formación del contexto cultural, social y económico de la región y del estado, demostrando así su importancia mismo que pasando por diversas dificultades desde la llegada de los primeros inmigrantes polacos en la región.

Algunos de los principales aspectos son el tema de la agricultura, que se desarrolló en la región después de la llegada de los polacos, la relación idiomática con la creación. Las escuelas polacas y el tema de la alimentación, con la introducción de técnicas eslavas para la conservación y producción de alimentos, que se difundió en toda la región a posteriori. (DOUSTDAR, 1990)

La mayoría de los inmigrantes polacos que se establecieron en la región alrededor de Curitiba/PR provenían de un origen campesino, en gran parte analfabetos, que llegaron a Brasil debido a las promesas de tierra fértil y paz, algo diferente de lo que fue en Europa durante siglos XIX y XX. (TURBANSKI, 2005)

Debido a esto, hubo un proceso de aislamiento social del grupo de los migrantes polacos en sus colonias, debido a una marginación social y cultural, y que mantuvo solo 
relaciones comerciales, como la ventas de vegetales producidos en sus colonias, en los centros urbanos. (DOUSTDAR, 1990)

Este proceso tuvo lugar durante décadas, intensificándose principalmente durante la Era Vargas (1930-1945), cuando el entonces presidente Getúlio Vargas instituyó una prohibición sobre las manifestaciones culturales, idiomáticas y étnicas de los extranjeros en Brasil debido a la asociación con el Nazismo. (DOUSTDAR, 1990)

Esto reafirmó y potenció el aislamiento social de los inmigrantes, de la primera y segunda generación de descendientes de inmigrantes europeos, incluidos los polacos de los alrededores de la región Curitiba/PR, en sus nichos sociales regionales, haciéndolos crear cada vez más esta identidad. Colonia aislada.

El contra proceso de esta página de la historia solo comenzó a fines de la década de 1960 y el inicio de la década de 1970, período de la dictadura militar brasileña, cuando el Brasil atravesó un intenso momento de industrialización y progresión forzada, que condujo a la expansión de la red y las áreas urbanas de las regiones al entorno de la ciudad de Curitiba/PR. (TAVARES, 2004)

Este proceso acercó las áreas urbanas y rurales de la región metropolitana de Curitiba/PR, lo que obligó a los residentes de la región a integrarse con el entorno urbano, en un momento en que los descendientes de inmigrantes polacos de la región ya estaban en la cuarta generación.

Sin embargo, incluso con la proximidad del espacio urbano, la mayoría de las colonias polacas alrededor de Curitiba/PR todavía constituyen hoy el "cinturón verde" de la región de Curitiba/PR, fuente de producción hortícola en la región, y considerado por Wachowicz, “o primeiro cinturão verde organizado por imigrantes no Brasil’". (WACHOWICZ, 1988, p.146)

Con una producción anual promedio de 12 mil toneladas de batatas y 13 mil toneladas de maíz, un ejemplo es Colônia Murici, una de las principales colonias polacas en la Región, que es responsable de la mayor parte de la producción, y es el mayor productor de este tipo de cultura en la región del cinturón verde de Curitiba/PR. (IPARDES, 2019)

Sin embargo, la importancia y el legado de la inmigración polaca, y de sus descendentes, en la región de Curitiba/PR no está limitada a solo elementos económicos, como la producción rural de alimentos, sino también en todo el contexto cultural y social de la región.

Herencias culturales pueden transformar las ciudades de modo estructural, sea de modo positivo o negativo. Un ejemplo que puede ser visto en muchas ciudades en toda Sudamérica, y principalmente en Brasil, son de las resignificación y cambio de funcionalidad 
RELACult - Revista Latino-Americana de Estudos em Cultura e Sociedade

Revista Latinoamericana de Estudios en Cultura y Sociedad | Latin American Journal of Studies in Culture and Society V. 06, $\mathrm{n}^{\circ}$ 03, set-dez., 2020, artigo no 1927 | claec.org/relacult | e-ISSN: 2525-7870

de sitios urbanos en territorios donde hay fuerte influencia cultural étnica y que son materializadas por las actividades turísticas. (PAES, 2012; PISARSKI JUNIOR, 2019)

De modo a ilustrar este apuntamiento sobre la resignificación de sitios urbanos en función de herencias culturales étnicas y su materialización por la actividad turística, las figuras 3 y 4 ejemplifican la herencia cultural étnica polaca en la ciudad de Curitiba/PR con relación a sitios turísticos:

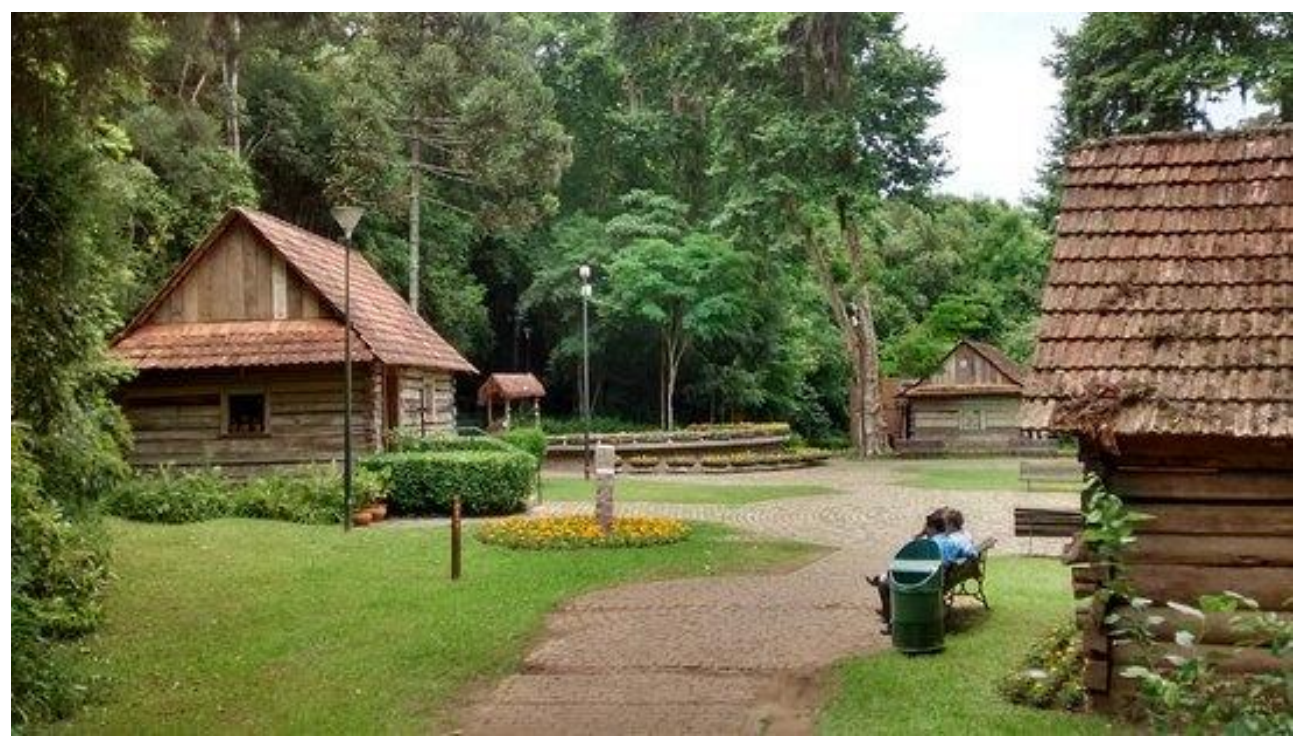

Figura 3 - "Bosque João Paulo II" / Memorial de la inmigración polaca Fuente: el autor (2020)

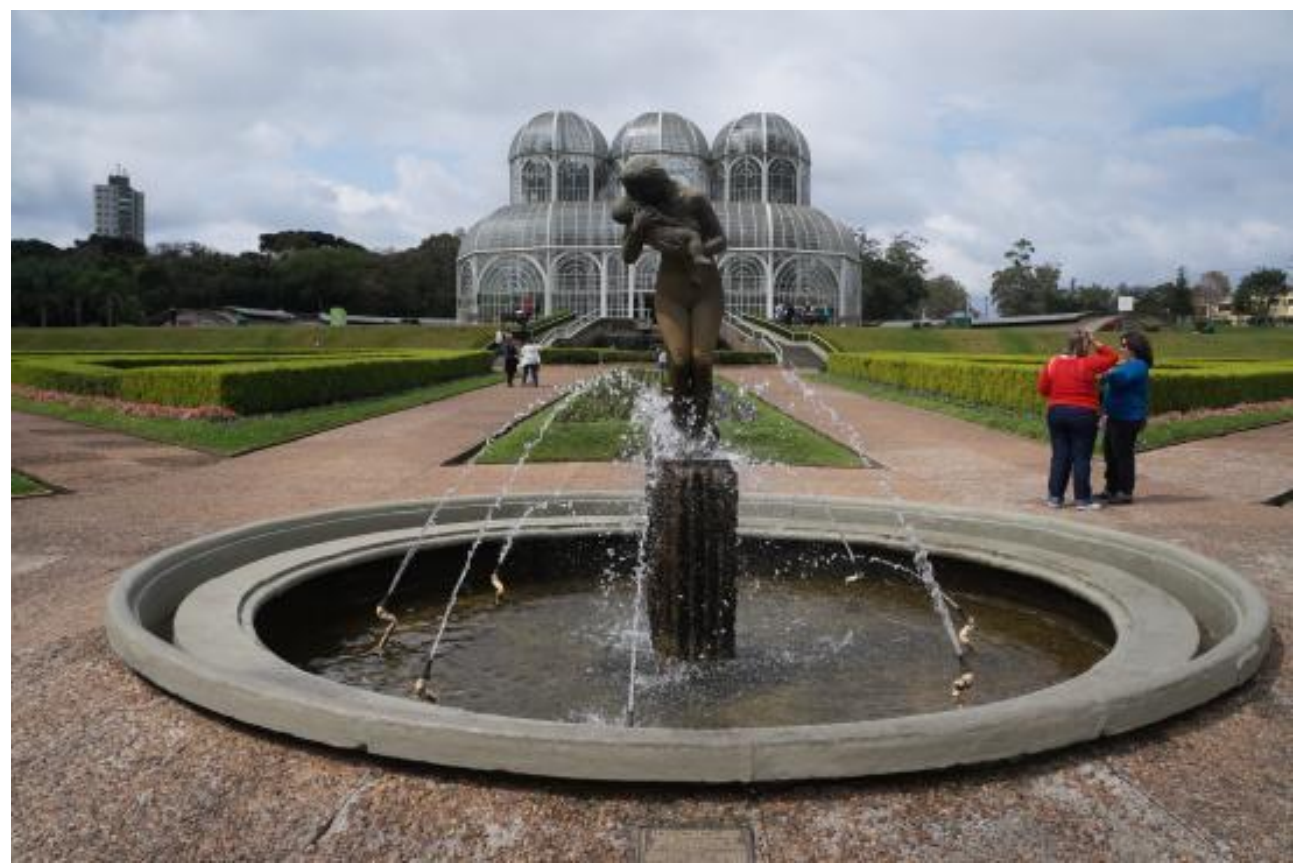

Figura 4 - Estatua “Amor Materno”, en el Jardín botánico de Curitiba/PR

Fuente: el autor (2020) 
Estos dos ejemplos, en figura 3 donde se puede ver el bosque en homenaje a la inmigración polaca para Curitiba/PR y la figura 4 de la estatua "Amor Materno" en homenaje a las madres polacas, obra del artista polaco João Zaco Paraná, ejemplifican como esta herencia cultural puede ser vista de modo material en la ciudad.

Otros ejemplos importantes de la importancia de la inmigración polaca en la región es la presencia de varios artistas, políticos, escritores, investigadores, maestros y músicos polacos y descendientes de polacos, que están intrínsecamente vinculados a la historia y el contexto cultural de la región Curitiba/PR.

Para ejemplificar algunas de estas grandes personalidades, polacos y descendientes de polacos, relevantes para el contexto cultural y social de la región de Curitiba/PR, se elaboró una tabla (tabla 1) que contiene el nombre de la personalidad y cuál es su área de actividad e impacto.

Tabla 1 - Personalidades polacas y su relevancia

\begin{tabular}{|c|c|}
\hline NOMBRE & ACTIVIDAD \\
\hline Paulo Leminski & Escritor e Poeta \\
\hline João Zaco Paraná & Escultor y Pintor \\
\hline Márcia Széliga & Escritora y llustradora \\
\hline Zbigniew Morozowicz (Henrique de Curitiba) & Músico y Compositor \\
\hline João Urban & Fotógrafo \\
\hline Everly Guiller & Artista Plástica \\
\hline Milena Morozowicz & Bailarina \\
\hline Francisco Lachowski & Modelo \\
\hline Jaime Lerner & Arquitecto y Político \\
\hline Jorge Samek & Político y Ingeniero \\
\hline Ruy Wachowicz & Profesor y Escritor \\
\hline
\end{tabular}

Fuente: el autor (2020)

Como es posible verificar, hay una gran cantidad de personalidades que se extienden desde el campo del arte a la política y que tienen sus raíces en la cultura de la ciudad de Curitiba/PR y el estado de Paraná, en un período de menos de 1 siglos y medio de inmigración polaca en la región, lo que demuestra su importancia.

También es necesario comprender que esta relación todavía permanece viva en Curitiba/PR, sea con los grupos folclóricos polacos (Wisla, Junak, Wawel, Wiosna e Wesoly Dom), las organizaciones culturales (Casa da Cultura Polonia-Brasil, Braspol, Clube Juventus, Sociedade Tadeusz Kosciuszko, Sociedade Abranches e Sociedade Marechal 
Pilsudski), las actividades propuestas por el Consulado-General de Polonia en Curitiba/PR y por la Iglesia católica, por medio de la Misión Católica Polonesa en Brasil.

\section{Conclusiones}

La inmigración polaca, que comenzó debido a factores políticos en Europa, cambió abruptamente la historia de un grupo étnico y encontró en Brasil un refugio para comenzar una nueva fase, a pesar de que encontró varias dificultades desde la llegada de los primeros migrantes.

En el estado de Paraná, y especialmente en la región de la ciudad de Curitiba/PR, esto no fue diferente, lo que provocó una consecuencia de aspectos que hasta hoy puede ser vista de modo material y subjetivo en la realidad de la ciudad de Curitiba/PR y en su región metropolitana.

En estos procesos, se destacan la colonización de regiones en los alrededores del área urbana de Curitiba/PR, lo que demuestra las raíces de lo que puede señalarse como marginación de la inmigración polaca en la región, sea el desfavorecimiento en la distribución de las tierras o por el preconcepto social por parte de los inmigrantes alemanes y posteriormente los brasileños.

Otro aspecto que demuestra los reflejos de la inmigración en la actualidad es la composición étnica del "cinturón verde" de la región de Curitiba / PR que, aunque no solo tiene descendientes de inmigrantes polacos, tiene una gran cantidad de descendientes de este grupo étnico.

En la cuestión del patrimonio cultural material de la ciudad de Curitiba/PR, es posible notar que la inmigración polaca en la región fue marcante, sea por la creación de un memorial para recordar esta etnia, que es un de los principales puntos turísticos de la ciudad, como en diversas obras artísticas por la ciudad, siendo la mas famosa la estatua en frente al principal punto turístico de Curitiba/PR.

Sin embargo, al demostrar que los impactos y el legado de la inmigración polaca no se limitaron a las colonias establecidas alrededor de la ciudad o solamente a patrimonios materiales,este trabajo demostró un gran numero de personalidades artísticas, académicas y políticas de reconocimiento nacional que son polacas, y descendientes de polacos, que son el resultado de este proceso de inmigración. 
De esta manera, es posible afirmar que la inmigración polaca trajo un legado cultural, social y economico que sigue siendo, hasta la actualidad como un elemento central de la construcción de la sociedad en la región de Curitiba/PR, un elemento que no se ve de forma aislada en esta región, sino en otras regiones de Brasil, como Río de Janeiro, São Paulo y Rio Grande do Sul, y en otros países latinoamericanos, como Argentina y Mexico.

\section{Referencias:}

ADAMOSKI, T. Comer para lembrar a alimentação e a preservação da identidade étnica polonesa nas colônias murici e mergulhão. Caderno de estudos e pesquisa do turismo, Curitiba, v. 2, p. 80-106, dez. 2013.

BAHL, M. Legados étnicos \& oferta turística. Curitiba, Juruá. 2014

BUENO, W. L. Curitiba, uma cidade bem-amanhecida: vivência e trabalho das mulheres polonesas no final do século xix e nas primeiras décadas do século xx. 1996. $178 \mathrm{f}$.

Dissertação (Mestrado) - Curso de História, Universidade Federal do Paraná, Curitiba, 1996.

DOUSTDAR, N. M. Imigração polonesa raízes históricas de um preconceito. Curitiba. 1990.

GIL, A. C. Como elaborar projetos de pesquisa. São Paulo: Atlas, 2002

GLUCHOWSKI, K. Os poloneses no Brasil. Porto Alegre: Rodzicz \& Ordakowski, 2005.

GRITTI, I. R. Imigração e Colonização Polonesa no Rio Grande do Sul: a emergencia do preconceito. Porte Alegre: Martins Livreiro, 2004

IAROCHINSKI, U. Saga dos Polacos. Curitiba: Gráfica Mansão, 2000.

IPARDES, Caderno Estatístico: Município de São José dos Pinhais. Paraná: IPARDES, 2019.

KRAVCZYK, M. V. Polfest: A construção da identidade polonesa em Guarani das MissõesRS. Porto Alegre: LUME, 2013.

PAES, M. T. D. Refuncionalização turística de sítios urbanos históricos no Brasil: das heranças simbólicas à reprodução de signos culturais. Revista Geografia, Rio Claro, v. 37, n. 2, p. 319-334, 2012.

PISARSKI JUNIOR, M. R. Tradição alimentar polonesa e suas interfaces com o turismo no distrito de Colônia Murici, São José dos Pinhais/PR. Dissertação (Mestrado em Turismo) Setor de Ciências Humanas Universidade Federal do Paraná, Curitiba, 2019.

PISARSKI JUNIOR, M. R.; SOUZA, S. do R. de. As tradições alimentares dos imigrantes poloneses em Curitiba (PR) e região metropolitana: seu legado étnico e sua potencialidade turístico-cultural, Revista X, Curitiba/PR, v. 15, n. 6, p. 360-377, 2020. 
POLANCZYK, A. J. O Imigrante Polonês e a Colônia Guarani. Porto Alegre: Renascença: Edigal, 2010.

REIS, A. L. C.; SILVEIRA, M. A. T. da. A imigração polonesa no território paranaense. Curitiba, 2008. Disponível em:

<https://geografiatecnologia.wikispaces.com/file/view/projeto.pdf $>$.

TELEGINSKI, N. M. Comeres, memórias e práticas: A transmissão da culinária polonesa entre descendentes de imigrantes no centro-sul do Paraná. In: Encontro Estadual de História da ANPUH-SP, 12., 2014, Santos, Anais eletrônicos... São Paulo: ANPUH-SP, 2014. p. 2238 .

TELEGINSKI, N. M. Sensibilidades na cozinha: a transmissão das tradições alimentares entre descendentes de imigrantes poloneses no centro-sul do Paraná, século XX. 355 f. Tese (Doutorado em História) - Setor de Ciências Humanas, Universidade Federal do Paraná, Curitiba, 2016.

TURBANSKI, S. D. Murici, Terra Nossa. Curitiba: Amaro, 2005.

WACHOWICZ, R. C. As escolas da colonização polonesa no Brasil. Curitiba: Anais da Comunidade Brasileiro-Polonesa. vol. VII, 1970.

WACHOWICZ, R. C. História do Paraná. Curitiba: Vicentina, 1988.

WACHOWICZ, R. C. O camponês polonês no Brasil. Curitiba: Fundação Cultural de Curitiba/Casa Romário Martins, 1981. 